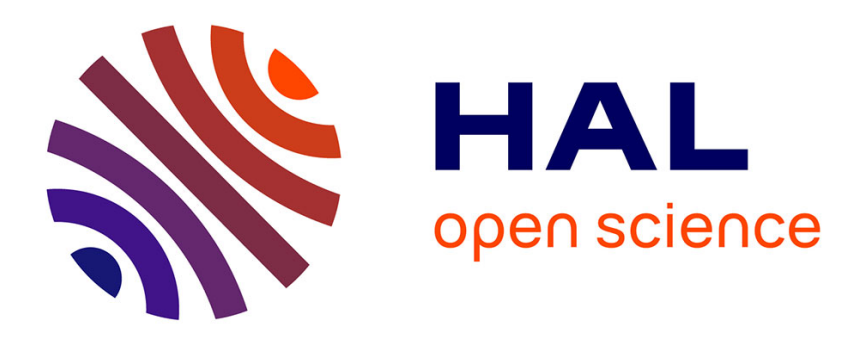

\title{
A Workload Control Procedure for an FMC integrated in a Job Shop
}

\author{
Michael Hoeck
}

\section{To cite this version:}

Michael Hoeck. A Workload Control Procedure for an FMC integrated in a Job Shop. International Journal of Computer Integrated Manufacturing, 2008, 21 (06), pp.666-675. 10.1080/09511920701501761 . hal-00513394

\section{HAL Id: hal-00513394 https://hal.science/hal-00513394}

Submitted on 1 Sep 2010

HAL is a multi-disciplinary open access archive for the deposit and dissemination of scientific research documents, whether they are published or not. The documents may come from teaching and research institutions in France or abroad, or from public or private research centers.
L'archive ouverte pluridisciplinaire HAL, est destinée au dépôt et à la diffusion de documents scientifiques de niveau recherche, publiés ou non, émanant des établissements d'enseignement et de recherche français ou étrangers, des laboratoires publics ou privés. 


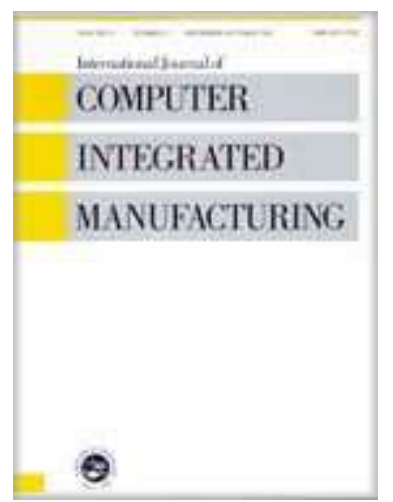

\section{A Workload Control Procedure for an FMC integrated in a Job Shop}

\begin{tabular}{|r|l|}
\hline Journal: & International Journal of Computer Integrated Manufacturing \\
\hline Manuscript ID: & TCIM-2006-IJCIM-0118.R1 \\
\hline Manuscript Type: & Original Manuscript \\
\hline Date Submitted by the \\
Author: & 18 -Apr-2007 \\
\hline Complete List of Authors: & $\begin{array}{l}\text { Hoeck, Michael; University of Hamburg, Institute of Industrial } \\
\text { Management }\end{array}$ \\
\hline Keywords: & $\begin{array}{l}\text { SCHEDULING, LOT SIZING, FLEXIBLE MANUFACTURING, } \\
\text { SIMULATED ANNEALING }\end{array}$ \\
\hline Keywords (user): & \\
\hline
\end{tabular}

\section{S ScholaroNE \\ Manuscript Central}




\section{A Workload Control Procedure for an FMC integrated in a Job Shop}

\section{MichAEL HOECK}

University of Hamburg, Department of Industrial Management, 20146 Hamburg, Germany

Email: hoeck@econ.uni-hamburg.de,Tel.: ++49-40-42838-4708, Fax: ++49-40-42838-6496

This paper describes an order release and loading technique, which considers the routing as well as the machine flexibility of a modern job shop production. The workload control approach involves three steps. In a first step 'lead orders', i.e. urgent production orders that are either processed on a known bottleneck or are of high value, are identified. Afterwards transfer batches of the lead part types are calculated using the aspired machine time as a control parameter. This parameter defines an adequate processing time of a machining center before it is set up for a new job. Finally, the bottom-line workload of the machining centers is determined by allocating and sequencing transfer batches. The procedure is tested by a simulation program that replicates the performance of the production facility of a machine manufacturer, consisting of a Flexible Manufacturing Cell that is embedded into a job shop production for heavy parts.

Keywords: Scheduling, Lot Sizing, Flexible Manufacturing, Simulated Annealing 


\section{Introduction}

Increasing cost pressure and competition has led to a further automation of the manufacturing process, while at the same time the proliferation of numbers and varieties of products require more flexible production techniques (Molina et al. 2005). Hence, many companies have invested in modern machining equipment, such as Flexible Manufacturing Cells (FMCs), which are designed to achieve the efficiency of automated large scale production whilst retaining the flexibility of low volume job shop production. In these highly automated systems a number of $\mathrm{CNC}$ machine tools are closely linked via work and tool handling facilities, operating under the supervisory control of a computerized cell controller (Rahimifard and Newman 1999). These cells are typically integrated into a conventional job shop production which increases the complexity of shop floor control (Yin et al. 2004, Cheung et al. 2000, Bauer et al. 1991). The versatility of flexible manufacturing technologies provides scope for several routes of a part type and can be utilized to alleviate bottlenecks. Furthermore additional constraints, e.g. the limited number of tool slots at each work center, need to be considered scheduling orders in a modern job shop environment.

A number of advanced production planning and control-systems, such as SAP R/3's PPMRP-Module, include special routines for 'lead production orders' to reduce complexity. Lead production orders are identified by the scheduler in the order release phase and are characterized by having a high urgency as well as (i) tasks that are performed on a bottleneck resource or (ii) part types with high capital tie-up costs. A bottleneck is defined as any resource whose capacity is less than the demand placed upon it. (Chase et al. 2005, pp. 670.) By differentiating between lead and other orders the active load of a shop floor is divided into two classes of jobs that are scheduled successively. At first lead orders are scheduled subject 
to tooling constraints to ensure a timely production. The remaining capacity is then filled with the remaining jobs based on the tool allocation identified in the first step.

\section{Problem Statement}

Workload control (WLC) is generally used as a rough-cut control technique to synchronize the manufacturing processes of a job shop production and successive production stages, like final assembly (Stevenson et al. 2005). Furthermore, WLC can be applied to control the internal material flow within a production stage (Breithaupt 2002). In practice, however, planning and control of an FMC is often executed isolated from the rest of the work centers (Stecke 1983, Grieco et al. 2001), so that the advantages of a modern job shop, such as the ability to alleviate bottlenecks, are only partially utilized. An efficient WLC approach should include a loading procedure that performs lot sizing and scheduling simultaneously to find an appropriate load balance between the FMC and other machine groups.

In modern job shops, where considerable routing flexibility exists, batch sizing and routing may significantly affect throughput and work-in-process inventory. Several research studies and experimental investigations have analyzed the effect of batching and routing decisions in a job shop using Queuing Network Models (Karmarkar 1985, Calabrese and Hausman 1991, Van Nieuwenhuyse and Vandaele 2006). These models show the potential improvement that can be achieved by simultaneous lot sizing and scheduling. On the other hand, queuing models define performance in terms of long-run, steady-state measures, while the current state of the facility as well as precedence constraints are not considered. For operational lot sizing and scheduling decisions a number of Dynamic Programming approaches and Branch-\&Bound-Procedures have been proposed (Solomon 1991, Fleischmann 1990). Most optimization techniques are restricted to single facility problems, if more than one item has to be 
scheduled and neglect the important characteristics of a modern job shop production, such as alternative process plans as well as multiple resources per operation, e.g. machine and tool magazine capacity. Also several heuristic procedures have been introduced. Arikan and Erol (2006), for instance, apply two local search techniques - simulated annealing and tabu search for the part selection and tool allocation problem in flexible manufacturing systems, similar to Sarma et al. (2002). Wang et al. (2006), on the other hand, describe specific heuristics for different classes of scheduling problems with multi-operation jobs in partially overlapping systems, while Golmakani et al. (2006) deal with on-line scheduling and control problems of FMCs.

In the following sections we will introduce an approach to release, batch and sequence orders in a modern job shop considering multiple constraints as well as alternative routings. The aim of the procedure is to find a good allocation and sequence of the production orders subject to organizational and technological constraints. The rest of the paper is organized as follows: In section 3 the basic steps of the workload control procedure are described in detail. Afterwards the approach is tested by a simulation program that replicates the performance of a real-world production facility, which is described in section 4.

\section{Workload Control Procedure}

The WLC procedure should be applied rolling through time and comprises three steps: (1) In a first step the 'urgency' of arriving jobs is determined by subtracting the estimated lead time from the due date. Only those orders are released to the shop floor whose planned starting date is within a previously defined time horizon (= order release window). (2) Afterwards the transfer batches of the production orders are calculated using the Aspired Machine Time (AMT) as a control parameter. (3) Finally, the process batch sizes of the jobs are determined by sequencing the transfer batches on the machining centers. 


\subsection{Setting the release window}

Analogous to the load-oriented order release (Bechte 1988, Breithaupt 2002) all arriving jobs are placed in a backlog, which serves as a buffer against fluctuations in the incoming order stream and is controlled by a parameter called the 'order release window'. By this control parameter the active load of a shop floor is divided into those production orders considered urgent and other jobs that can be scheduled later. In addition, particular attention should be given to tasks that are performed on a bottleneck resource and part types with high capital tieup costs, to identify lead orders. Potential bottlenecks can be machining centers subject to random downtimes or high setup times as well as special tools or fixtures needed to perform an operation. To reduce the work-in-process inventory only lead orders whose planned starting date (= due date - planned lead time) lies within the predefined time horizon are released to the shop floor. The order release window, which starts with the actual period, should be a multiple of the planning horizon of the scheduling system. Enlarging the release window can reduce the tardiness of the production orders because jobs that are not urgent are pre-released, whilst at the same time the workload and work-in-process inventory of the job shop as well as the flow time of the jobs will increase. On the other hand, a release window that is too small results in high idle times at the machining centers and may not shorten the flow time of the production orders. We refer to Land and Gaalman (1996) for a more detailed discussion on the conflict between timing and balancing within the order release function and the underlying assumptions of different WLC approaches regarding the job mix on the shop floor. Overall, setting the release window is an instrument to control the total workload and tardiness in a job shop. Withholding jobs from the shop floor enables management to delay final production decisions. It thereby reduces, for instance, waste due to cancelled orders and facilitates a later ordering of raw materials. 


\subsection{Calculating the transfer batches}

The basic idea of transfer batches became popular through the introduction of the Period Batch Control (Burbidge 1960) and Kanban approach (Sugimor et al. 1977) and was afterwards adopted by OPT (Fry et al. 1992) to control the material flow in a job shop production. A transfer batch of a part type is defined as the number of parts moved between resources and the smallest lot size before a machining center can be set up to a new order. By sequencing transfer batches of multiple items (jobs) on a machine, which will be described in section 3.3, the process batch of an operation is determined. As a consequence, the process batch of a part type may differ from the transfer batch and vary from one work center to the other. Contrary to conventional MRP, which determine lot sizes for each part type separately minimizing assumed carrying and set up costs, lot sizing is here based on a systems approach, which involves the current state of the shop floor and the overall goal of production control. Furthermore, it provides the advantage that batching decisions are transferred to the shop floor, which usually has more accurate information on constraints.

Since the real holding and set up costs are not known in advance, the aim of transfer batch sizing is to minimize flow time. A key factor, next to potential, yet unknown bottlenecks that retards the material flow in a job shop are high deviations in the processing time of the jobs. If all batches were to be passed from one work center to another within a similar cycle time, the queuing time on the shop floor could be reduced to a large extent. Equivalent to a traffic guidance system an increased throughput can be achieved by introducing a suggested 'speed' for the part types or an Aspired Machine Time (AMT). This control parameter defines an adequate processing time of a machining center before it is set up for a new job. If a production order exceeds the AMT, it is split into smaller and therefore faster transfer batches, thus reducing 'traffic jams' in the job shop. An AMT of a machining center 
correlates with the average set up time, which includes the time to replace worn-out or broken tools, the time for tool changes to produce a different subset of the given part types, and the time to assemble or mount new fixtures. An appropriate AMT will lead to small transfer batches, which shorten the flow time of the production orders. If the AMT is set too low, shop time is consumed with non-productive set ups; the resulting high level of traffic density will cause greatly increased congestion. On the other hand, a high AMT and therefore large transfer batches tie up machines for extended periods of time, thus increasing the unit flow time. Next to the set up times the 'optimal' AMT value depends on the released workload and job mix of the shop floor. If the total workload of a work station increases, the AMT value should increase too.

The calculation of transfer batches involves two steps. In a first step the transfer batch size of a part type $\mathrm{j}$ is determined independently from the net requirements of the part types. To ensure a minimum cycle time in the work flow of a part type the transfer batch size is set equal to the maximum relative production rate, which is the ratio of the $\mathrm{AMT}\left(\mathrm{AMT}_{\mathrm{m}}\right)$ and processing time of one part at each machining center $\mathrm{m}\left(\mathrm{p}_{\mathrm{jm}}\right)$ stated in the NC Program. Since a production order usually runs over more than one machining center the transfer batch size of a part type $\mathrm{j}\left(\mathrm{TBS}_{\mathrm{j}}\right)$ is calculated as

$$
T B S_{j}=\operatorname{Max}\left[\frac{A M T_{m}}{p_{j m}} \forall m \in M_{j}\right] \quad \forall j
$$

with $\mathrm{M}_{\mathrm{j}}$ being the set of all machining centers $\mathrm{m}$, where part type $\mathrm{j}$ is processed including alternative routes. By this approach all potential bottlenecks in a job shop which usually require an above average set up time and therefore high AMT are considered. 
In a second step the number of batches that have to be produced is calculated by dividing the net requirement of a part type by the transfer batch size. Performing the above division may not result in an integer value. To completely satisfy the requirements of the part types, leftovers should either be spread over the existing transfer batches or added to one transfer batch.

To illustrate the calculation of transfer batches and the effect of the AMT, we will discuss a sample production program of a job shop in Table 1, assuming that 6 part types are processed on 4 machines. Table 1 contains basic data, i.e. the net requirements (original lot sizes) and machine time per part as well as the mean processing time of the original batch size.

Insert Table 1 about here

The sample program is characterized by a relatively high standard deviation of the mean batch processing times $(7.8 \mathrm{~h})$, which is typical for a job shop production. An AMT of 200 minutes for all four machining centers will lead to the following relative production rates and transfer batch sizes of the part types (see Table 2). The number of transfer batches results from the division of the net requirement by the maximum relative production rate of a part type highlighted in Table 2 - whereby leftovers are spread equally over existing transfer batches.

Insert Table 2 about here

Here part types 1, 4 and 5 are produced with their original net requirements, while items 2, 3 and 6 are transferred through the job shop in smaller batches. In this example an AMT of 200 minutes reduces the standard deviation in the mean processing time of the batches by $75 \%$ to $1.9 \mathrm{~h}$, which will shorten the waiting time of the jobs at each machining center. As shown in 
Table 2, not all part types (i.e. 1 and 5) may reach the AMT of every resource, because of low net requirements. The mean processing time of the transfer batches in a job shop is therefore a hyperbolic function that decreases the smaller the AMT is (see Fig. 4). At the same time the average number of transfer batches expands exponentially resulting potentially in higher set up times. The actual set up times, however, are determined by sequencing the transfer batches on the shop floor, which will be described in the following section.

\subsection{Sequencing the transfer batches}

In a final step of the WLC procedure the process batches of the orders as well as the adequate loads of the machining centers are determined by allocating and sequencing the transfer batches. In many shops accurate cost data is not available, therefore scheduling is usually based on time-oriented objectives, e.g. minimizing the maximum lateness or mean lead time of the jobs that correlate with the cost goals. These performance measures often change from one planning period to the other (Pinedo 1997). Hence, a loading procedure needs to be flexible regarding the objective function so that it can be adapted to the priorities of the scheduler.

As mentioned in the previous section, scheduling of transfer batches provides the advantage that lot sizes of a part type may vary from one work center to the other. In order to reduce the flow time of the jobs, large lot sizes should be placed on the bottleneck resources, while nonbottlenecks could produce smaller batches. Further, the process batches of a part type may overlap in time (see Fig. 1), which is also a common approach to reduce lead time in a production facility. Additionally the routing flexibility, i.e. the ability to perform operations by more than one work center, can be utilized to reduce the flow time of the production orders. Routing flexibility occurs in a job shop whenever machining centers with similar 
capabilities exist, that are tooled to a certain extent identically. As a consequence of automatic tool interchange modern machining centers are able to process several operations with virtually no set up times between operations. This versatility allows a considerable flexibility in assigning operations along with associated required tooling among the machines. If two identically tooled work centers, e.g. in an FMC (M3) and a conventional shop (M4) exist, bottlenecks can be alleviated and process batches of a part type can be parallelized.

Insert Figure 1 about here

As a result of the machine and routing flexibility, scheduling in a modern job shop facility has a major impact on performance, but is rather complex, especially if additional constraints, e.g. shift or tool magazine capacities, need to be considered. For this reason an efficient heuristic approach is proposed, which combines regular dispatching rules and local search procedures, like Simulated Annealing (Kirkpatrik et al. 1993; Cerney 1985), or Tabu Search (Glover 1986). The basic idea of local search is to generate - in an iterative process - new solution proposals based on a feasible seed solution which are accepted under certain conditions for further neighborhood search. Contrary to conventional iterative improvement techniques these procedures also accept inferior solutions for further neighborhood search, in order to escape local optima and to increase the likelihood of finding the global optimum. A local search procedure involves three steps:

\section{(1) Generating an initial seed schedule}

In a first step an initial seed schedule $\mathrm{Sj}$ is generated, which can be provided by any heuristic method. For job shop scheduling problems various dispatching rules have been put forward 
(Baker 1974, Choi and You 2006). These single pass heuristics construct a schedule through a sequence of decisions on what seems locally best and the decisions once made are final. In comparison to other scheduling approaches, priority rules provide the advantage of low computation time and can be easily adapted to constraints. On the other hand they rarely find a 'near optimum' solution.

\section{(2) Neighborhood Search}

To improve an initial seed schedule, neighborhood search techniques, such as a pairwise interchange of operations or batches on a machine, can be applied. Several research studies (Aarts et al. 1994) have shown that the definition of a neighborhood structure $\mathrm{N}_{\mathrm{j}}$ is crucial for the performance of local search. In literature search procedures are often applied to the classical Job Shop Problem (JSP), i.e. to minimize the makespan in a conventional shop (Van Laarhoven et al. 1992). All search techniques have in common that they diminish the large set of possible neighboring solutions in order to increase the speed of search. Yet, most of them are restricted to the objective function of minimizing the makespan.

In the following we will apply a neighborhood search technique, which is also based on small neighborhoods, but flexible regarding the performance measures of production control. The neighborhood search implies a priority dispatching rule and interchanges alternatively dispatchable transfer batches. Each time a schedule is constructed by a dispatching rule the set of alternatively dispatchable transfer batches $o_{n}$ is recorded. Let then $S_{j}$ be a seed schedule and let $\mathrm{Q}_{\mathrm{mt}}$ denote the set of transfer batches waiting in queue to be processed on machining center $\mathrm{m}$ in period $\mathrm{t}$. Further, let $\tau$ denote the set of periods where more than one job is to be processed on a machine or a job-predecessor of an operation is finished. The local search procedure can then be stated as follows: 


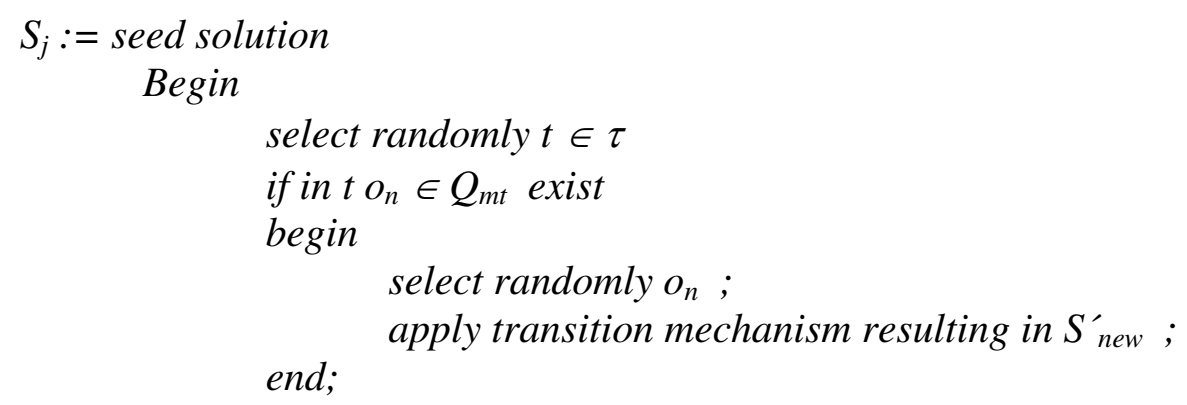

End;

for $t:=t+1$ to $T$ do priority rule dispatching

$S_{i}:=S_{\text {new }}$;

Here neighborhood search is focused on good heuristic solutions. Further, there are two transition mechanisms implemented (see Fig. 2(a) and 2(b)).

Insert Figure 2 about here

The first transition mechanism changes the sequence of jobs on a machining center by swapping a transfer batch $o_{1}$ - originally scheduled by a dispatching rule - and $o_{n}$ waiting in queue, if $\mathrm{o}_{\mathrm{n}}$ is a transfer batch of a different part type. The second transition mechanism utilizes the routing flexibility of the production orders and moves one of these transfer batches to an idle machining center, which can process the operation at the same starting point. After the pairwise interchange of operations or move of a transfer batch to another machining center, a dispatching rule is used to construct the schedule for the rest of the periods.

\section{(3) Conditions of acceptance}

Apart from the definition of the neighborhood there are several strategies to control local search, which is done by the conditions of acceptance. In the following sections, Simulated Annealing (SA) is applied that uses a controlled probability function to avoid being trapped in 
local optima. In SA worsening moves are accepted with the probability $\exp \{-\Delta \mathrm{C} / \mathrm{T}\}$, which is a function of the difference in objective values between the current and perturbed solution $(\Delta \mathrm{C})$ as well as the temperature $(\mathrm{T})$ as control parameter (van Laarhoven and Aarts, 1987).

\section{Industrial application and computational results}

The WLC procedure has been tested at a production facility of a major German manufacturer of cigarette and packaging machines, consisting of an FMC, which is embedded in a job shop production of heavy parts. The integrated FMC includes three work centers, which are 3-axis drilling and milling machines, connected by a monorail conveyor. There are three loading / unloading stations and 15 buffer stations. Next to the FMC there are $8 \mathrm{CNC}$ machine tools with two identical 5-axis omni-mills and two identical 3-axis horizontal drilling machines. In addition, the production facility consists of a conventional vertical drilling machine, a CNC vertical milling machine and a $\mathrm{CNC}$ vertical grinding machine, which is used to finish the parts. Extremely large part types are processed on a special CNC milling and drilling machining center. The production program of the job shop includes a wide range of part types, such as housings, bearings and holders etc., which are assembled at the next production stage. The parts are made of aluminum, plastic, cast iron and steel with average production requirements of 25 parts.

Our simulation study covers a planning horizon of 5 workdays (4800 minutes) with two 8hour shifts per day. The input data of the simulation program includes 10 master production schedules, each with 50 lead orders. The net requirements of the lead parts are determined by a uniform distribution in the interval $[5,55]$. Also, the arrival as well as the due dates of the production orders are chosen randomly from the discrete periods $[0,960,1920]$ and $[2880$, $3840,4800]$ respectively, assuming that starting and assembly dates are set by a central MPC- 
System on a daily basis. For each part type there are [1,5] operations to be performed, whereby the work centers of the FMC as well as the identical drilling and milling machines can be utilized alternatively. A simplification in operating the investigated job shop is established by tool standardization. All machining centers are tooled with a set of standard tools, which are frequently used during the operation. For the rest of the tools the strategy of difference tools is applied, meaning that only extra tools needed are loaded. The processing time of an operation varies between $[3,60]$ minutes per part with tool requirements of $[1,10]$ extra tools. However, the average change over time of a process batch is 30 minutes on all work centers in the shop. A total set up of a machining center - meaning that all unneeded tools are removed and new tool sets are loaded onto the magazine - occurs if an operation exceeds the actual tool magazine capacity. Otherwise it is assumed that the tools are loaded in advance, so that the set up time of an automatic tool exchange is zero. All machine tools of the FMC are equipped with local tool magazines that have a capacity of 30 extra tools, while the stand-alone $\mathrm{CNC}$ machines have a capacity of 20 extra tools.

At the FMC a process batch can be split into several FMC pallet orders, depending on the fixture layout necessary to produce a certain part type completely (see figure 3 ). The average refixturing time is 15 minutes for each mount, while the conveyor moves at a speed of 30 meters/minute. However, in our simulation model these complicating factors are ignored. The FMC program is determined at an aggregated level, whereby in the investigated shop floor fixtures are not a constraint.

Insert Figure 3 about here 
At present, the job shop scheduling is performed by a Shop Floor Control System using priority dispatching rules whilst the FMC is scheduled manually. The overall objective of production control is to minimize the mean flow time of the production orders.

The experimental investigation focuses on the last two steps of the described WLC procedure, namely the calculation and scheduling of the transfer batches. Since the setting of the order release window is equivalent to the load-oriented order release, its influence on the capacity utilization has been analyzed by several other earlier research studies (Zäpfel et al. 1992; Knolmayer 1991). To investigate the effect of the Aspired Machine Time (AMT) on the performance measures of the job shop we calculated the transfer batches (see section 3.2) on the basis of 9 AMT settings for each master production schedule, which were afterwards scheduled by a dispatching rule. Additionally, we analyzed the potential improvement of the mean flow time of the orders that can be achieved, if the described local search procedure is applied. Due to the probabilistic nature of SA it is necessary to carry out multiple runs on the same problem instance in order to get meaningful results. In this simulation study each 'macrorun' consists of 3 regular simulation runs for one acceptance parameter setting. In total, three parameter settings are used. The initial temperature (T) was set, so that (i) $98 \%$, (ii) $97 \%$ and (iii) $96 \%$ of the trial moves were accepted in the first neighborhood search and then lowered by the factor $0.97,0.98$ and 0.99 . These parameter settings cover a wide range of the solution space, whilst configuration (i) accepts greatly increasing transitions and configuration (iii) allows only minor uphill moves. Further, the number of searches $\mathrm{K}$ per iteration is set to neighborhood size (= number of alternatively dispatchable operations) of each accepted schedule. A simulation run is aborted after a local neighborhood has been searched randomly three times without any improvement of the best solution. All in all there were 810 simulations to compare, each representing a different combination of AMT (9), the priority dispatching rule and SA acceptance parameter configuration (9). In the following section we 
focus on the Shortest Processing Time (SPT)-rule to construct an initial seed schedule and for further neighborhood search.

In a first step the impact of the Aspired Machine Time (AMT) on the performance measures of the job shop is analyzed. Because of the similar set up times on all work centers, we apply only one control parameter for all the machining centers of the job shop to calculate the transfer batch sizes of the part types. Fig. 4 shows the mean processing time as well as the standard deviation of the processing times of the transfer batches in relation to the AMT, taking one order stock as an example. The AMT is stated here in percentage of the shift capacity (480 minutes) varying from 48 to 240 minutes.

In this test instance the average number of transfer batches per part type is close to one, if an AMT of $50 \%$ (240 minutes) is chosen, with a mean processing time of 330 minutes. Reducing the AMT from $50 \%$ to $10 \%$ will lead to smaller transfer batches with an average processing time of 90 minutes on each machining center, eventually reducing the processing time variability. At the same time the average number of transfer batches per part type increases exponentially to 5 batches, resulting in a proliferation of setups.

Insert Figure 4 about here

As mentioned before, the goal of transfer batch sizing is to minimize the average lead times of the production orders, which is equivalent to maximizing the throughput considering the WIP (lead orders) are fixed. Table 3 contains an overview of the performance measures of the job shop using the SPT-rule to schedule the transfer batches based on different AMT settings. The average flow time (MFT) of the part types is 1.73 days while the mean tardiness (MT) is 221 
minutes in the ten (deterministic) scenarios, each with 50 lead orders. Within the planning horizon the average utilization of the machining centers is $64 \%$.

Insert Table 3 about here

The results indicate that the shop floor performance is highly dependent on the AMT of the work centers. It can be observed that in particular the mean flow time as well as the mean tardiness can be reduced to a large extent, if production orders are split into smaller transfer batches. Contrary to the conventional MRP approach of scheduling part types with their net requirements or given lot sizes, process batches vary here from one work center to the other, overlap in time or are parallelized on identical machines, which reduces the average lead time by up to $50 \%$. For the investigated shop floor an AMT of $30 \%$ provides the best results, meaning that a potential bottleneck resource processes a transfer batch at least 144 minutes before it's set up for a new job. A further reduction of the AMT expands the mean lead time of the part types, since the number of transfer batches will increase over proportionately and shop time is consumed with nonproductive set ups. Overall, the calculation of the transfer batch sizes as well as sequencing the transfer batches using a priority dispatching rule is a matter of seconds on a personal computer, whilst the simulation program is written in $\mathrm{C}++$.

Insert Figure 5 about here

A further improvement of the mean lead time can be achieved by applying the described local search method. The results of the SA algorithm for different batch sizes are summarized in 
Figure 4. In comparison to the quality of the initial schedules created by an SPT-rule, the local search reduces the mean flow time by an additional $40 \%$ on average. As expected, major improvements $(48 \%)$ are achieved at a high AMT, i.e. large transfer batches, while smaller reductions result at the 'optimal' AMT level. Overall, the experimental study shows that scheduling has a much higher impact on performance than lot sizing for the investigated job shop. Due to the routing and machine flexibility of a modern job shop lead times are primarily determined by the routing of the part types and tool allocation and not so much by the (transfer) batch sizes.

\section{Conclusions}

In this paper we introduced a WLC approach in a modern job shop environment. The aim of the described procedure is not to create a minute-based timetable, but to find a good allocation and sequence of the production orders subject to organizational and technological constraints. At a first stage a rough-cut order release is performed to control the workload, work-inprocess inventory and tardiness in the job shop. Afterwards the 'urgent' production orders are batched and scheduled using a systems approach that can be adapted to the priorities of the scheduler. One control parameter of the WLC procedure is the Aspired Machine Time (AMT), which defines the adequate processing time of a machining center before it can be set up for a new job. The appropriate processing time of a machining center depends on the overall goal of production control and the current state of the job shop. As a result of the routing flexibility in a modern job shop bottlenecks are rarely known in advance or may shift within the planning period. Therefore one should apply a simulation run using a regular dispatching rule to determine the AMTs of the work centers, which takes only seconds on a regular PC. To improve a given schedule the described scheduling procedure can be applied, which combines regular dispatching rules and local search. For the investigated job shop 
facility the last step of the WLC procedure has the highest impact on the performance. Independent of the predetermined transfer batch sizes, the mean flow time of the production orders can be reduced to a large extent.

The described approach can easily be adapted to additional constraints, such as local buffer and workforce capacities. In general, scheduling constraints diminish the set of alternatively dispatchable operations, thus increasing the speed of local search. On the other hand, additional availability checks have to be performed, which prolong the computational time of heuristics. Therefore only 'hard' constraints that determine the feasibility of the schedules should be considered.

The WLC procedure can be embedded into the concept of virtual manufacturing cells (VMCs) (Nomden et al. 2006). A VMC is a group of resources dedicated to the manufacturing of part families, though this grouping may not be reflected in the physical floor layout (McLean et al. 1982). Depending on the job mix at a given time, machine centers across departments are identified in the production control systems as logical groups, instead of repositioning the machines to be adjacent to each other. This concept has gained considerable attention in small batch manufacturing with frequent changes in the job mix. 


\section{References}

Aarts, E., Van Laarhoven, P., Lenstra, J., Ulder, N., A Computational Study of Local Search Algorithms for job shop Scheduling, ORSA Journal of Computing, 1994, 6(2), 118-125. Arikan, M., Erol, S., Meta-heuristic approaches for part selection and tool allocation in flexible manufacturing systems, International Journal of Computer Integrated Manufacturing, 2006, 19(4), 315-325.

Baker, K., Introduction to sequencing and scheduling, New York et al. 1974.

Bauer, A., Bowden, R., Browne, J., Duggan, J., Lyons, G. (1991), Shop Floor Control Systems, London et al. 1991.

Bechte, W., Theory and Practice of Load Oriented Manufacturing Control, International Journal of Production Research, 1988, 26(3), 375-395.

Breithaupt, J., Land, M., Nyhuis, P., The workload control concept: theory and practical extensions of Load Oriented Order Release, Production Planning and Control, 2002, $7(1), 625-638$.

Burbidge, J., Standard Batch Control, Plymouth 1960.

Calabrese, J., Hausmann, W., Simultaneous Determination of Lot Sizes and Routing Mix in a job shop, Management Science, 1991, 37(8), 1043-1057.

Cerny, V., Thermodynamical Approach to the Traveling Salesman Problem, Journal of Optimization Theory and Applications, 1985, 45(1), 41-51.

Chase, R., Aquilano, N., Operations Management for Competitive Advantage, $11^{\text {th }}$ Edition, Boston et al. 2005.

Cheung, H., Yeung, W., NG, H., Fund, S., HSCF: a holonic shop floor control framework for flexible manufacturing systems, International Journal of Computer Integrated Manufacturing, 2000, 13(2), 121-138.

Choi, B., You, N., Dispatching rules for dynamic scheduling of one-of-a-kind production, International Journal of Computer Integrated Manufacturing, 2006, 19(4), 383-392.

Grieco, A., Semeraro, Q., Tolio, T., A Review of Different Approaches to the FMS Loading Problem, The International Journal of Flexible Manufacturing Systems, 2001, 13(4), 361-384.

Fleischmann, B., The Discrete Lot-Sizing and Scheduling Problem, European Journal of Operational Research, 1990, 44(3), 337-348. 
Fry, T., Cox, J., Blackstone, J., Hoffmann, T., An Analysis and Discussion of the Optimized Production Technology Software and Its Use, Production and Operations Management, 1992, 1(2), 229-242.

Glover, F., Future paths for integer programming and links to artificial intelligence, Computers and Operations Research, 1986, 13(5), 533-549.

Golmakani, H. Mills, J., Benhabib, B., On-line scheduling and control of flexible manufacturing cells using atomata theory, International Journal of Computer Integrated Manufacturing, 2006, 19(2), 178-193.

Karmarkar, U. S., Lot Sizes, Lead Times and In-Process Inventories, Management Science, 1987, 33(3), 409-423.

Kirkpatrik, S., Gelatt, C., Vecchi, M., Optimization by Simulated Annealing, Science, 1983, 220(4598), 671-680.

Knolmayer. G., A widely acclaimed method of load oriented job release and its conceptual deficiencies, in: G. Fandel, and G. Zäpfel (Eds.), Modern Production, Concepts, Berlin et al. 1991.

Land, M., Gaalman, G., Workload control concepts in job shops - A critical assessment, International Journal of Production Economics, 1996, Vol. 46/47, pp. 535-548.

McLean, C, Bloom, H, Hopp, T., The virtual manufacturing cell. In Proc. Fourth IFAC/ IFIP Conference on Information Control Problems in Manufacturing Technology, 1982, 105 111.

Molina, A., Rodriguez, C., Ahuett, H., Cortes, J., Ramirez, M., Jimenez, G., Martinez, S., Next-generation manufacturing systems: key research issues in developing and integrating reconfigurable and intelligent machines, International Journal of Computer Integrated Manufacturing, 2005, 18(7), 525-536.

Nomden, G., Slomp, J., Suresh, N., Virtual manufacturing cells: A taxonomy of past research and identification of future research issues, International Journal of Flexible Manufacturing Systems, 2006, 17(2), 71-92.

Pinedo, M., Commentary on An Exposition of Multiple Constraint Scheduling as Implemented in the Goal System, Production and Operations Management, 1997, 6(1), 25-27.

Rahimifard, H., Newman, S., The application of information systems for the design and operation of flexible machining cells, Journal of Intelligent Manufacturing, 1999, 10(1), 21-27. 
Sarma, U., Kant, S., Rai, R., Tiwari, M., Modeling the machine loading problem of FMSs and its solution using a tabu-search-based heuristic, International Journal of Computer Integrated Manufacturing, 2002, 15(4), 285-295.

Solomon, M., Deterministic Lotsizing Models for Production Planning, Berlin et al. 1991.

Stecke, K., Formulation and Solution of nonlinear integer production planning problem for a flexible manufacturing system, Management Science, 1983, 29(3), 273-288.

Stevenson, M., Hendry, L., Kingsman, B., A review of production planning and control: the applicability of key concepts in the make-to-order industry, International Journal of Production Research, 2005, 43(5), 869-898.

Sugimor, Y., Kusunoki, K., Cho, F., Uchikawa, S., Toyota Production System and Kanban System Materialization of Just-In-Time and Respect-For-Human System, International Journal of Production Research, 1977, 15(6), 553-564.

Van Laarhoven, P., Aarts, E., Lenstra, J., job shop Scheduling by Simulated Annealing, Operations Research, 1992, 40(1), 113-125.

Van Laarhoven, P.and Aarts, E., Simulated Annealing, Dordrecht 1987.

Van Nieuwenhuyse, I., Vandaele, N., A queueing model for a two-stage stochastic manufacturing system with overlapping operations, International Journal of Flexible Manufacturing Systems, 2006, 17(3), 175-199.

Wang, C., Ghenniwa, H., Shen, W., Scheduling multi-operation jobs in partially overlapping systems, International Journal of Computer Integrated Manufacturing, 2006, 19(5), 453462.

Yin, X., Chua, T., Wang, F., Liu, M., Cai, T., Yan, W., Chong, C., Zhu, J., Lam, M., A rulebased heuristic finite capacity scheduling system for semiconductor backend assembly, International Journal of Computer Integrated Manufacturing, 2004, 17(8), 733-749.

Zäpfel, G. and Missbauer, H., Production Planning and Control including Workload Control, Working Paper presented at the Seventh International Working Seminar on Production Economics, Igls 1992. 


\section{Tables}

\begin{tabular}{|c|c|c|c|c|c|c|}
\hline \multirow[t]{2}{*}{$\begin{array}{l}\text { Part } \\
\text { no. }\end{array}$} & \multirow{2}{*}{$\begin{array}{c}\text { Net } \\
\text { Requirements } \\
\text { (original batches) } \\
\text { [units] }\end{array}$} & \multicolumn{4}{|c|}{$\begin{array}{l}\text { Processing time per part at machining center } \\
\text { [minutes] }\end{array}$} & \multirow{2}{*}{$\begin{array}{c}\varnothing \text { Processing } \\
\text { time per } \\
\text { original batch size } \\
\text { [minutes] }\end{array}$} \\
\hline & & M1 & M2 & M3 & M4 & \\
\hline 1 & 100 & 5 & 2 & 1 & 4 & 300 \\
\hline 2 & 420 & 2 & 1 & 2 & 3 & 840 \\
\hline 3 & 200 & 5 & 2 & 4 & 3 & 700 \\
\hline 4 & 50 & 20 & 10 & 2 & 20 & 650 \\
\hline 5 & 10 & 60 & 20 & 30 & 20 & 325 \\
\hline 6 & 300 & 10 & 5 & 4 & 2 & 1575 \\
\hline
\end{tabular}

Table 1 Master production program of a job shop

\begin{tabular}{|c|c|c|c|c|c|c|}
\hline $\begin{array}{c}\text { Part } \\
\text { no. }\end{array}$ & \multicolumn{4}{|c|}{$\begin{array}{l}\text { Relative production rate of the part types } \\
\qquad \text { [units/AMT] }\end{array}$} & $\begin{array}{c}\text { Number \& Size } \\
\text { of Transfer } \\
\text { Batches } \\
\text { [units] }\end{array}$ & $\begin{array}{l}\varnothing \text { Processing } \\
\text { time per batch } \\
\text { [minutes] }\end{array}$ \\
\hline 1 & 40 & 100 & 200 & 50 & $1 \times 100$ & 300 \\
\hline 2 & 100 & 200 & 100 & 66.67 & $2 \times 210$ & 420 \\
\hline 3 & 40 & 100 & 50 & 10 & $2 \times 100$ & 350 \\
\hline 4 & 10 & 20 & 100 & 10 & $1 \times 50$ & 650 \\
\hline 5 & 3.33 & 10 & 6.67 & 10 & $1 \times 10$ & 325 \\
\hline 6 & 20 & 40 & 50 & 100 & $3 \times 100$ & 525 \\
\hline
\end{tabular}

Table 2 Calculation of transfer batch sizes

\begin{tabular}{|l|c|c|c|c|c|c|c|c|c|}
\hline $\begin{array}{l}\text { AMT } \\
\text { Performance } \\
\text { Measures }\end{array}$ & $10 \%$ & $15 \%$ & $20 \%$ & $25 \%$ & $30 \%$ & $35 \%$ & $40 \%$ & $45 \%$ & $50 \%$ \\
\hline Makespan [min.] & 4848.04 & 4922.44 & 4601.24 & 4789.24 & 4368.13 & 4274.13 & 4689.78 & 4875.56 & 4925.89 \\
\hline MFT [min.] & 1960.59 & 1941.73 & 1646.45 & 1285.51 & 1165.33 & 1519.94 & 1606.40 & 1656.87 & 2206.24 \\
\hline MT [min.] & 243.30 & 226.71 & 154.94 & 122.56 & 118.61 & 216.63 & 288.27 & 299.09 & 319.82 \\
\hline
\end{tabular}

Table 3 Performance measures of the job shop depending on AMT 


\section{Figures}

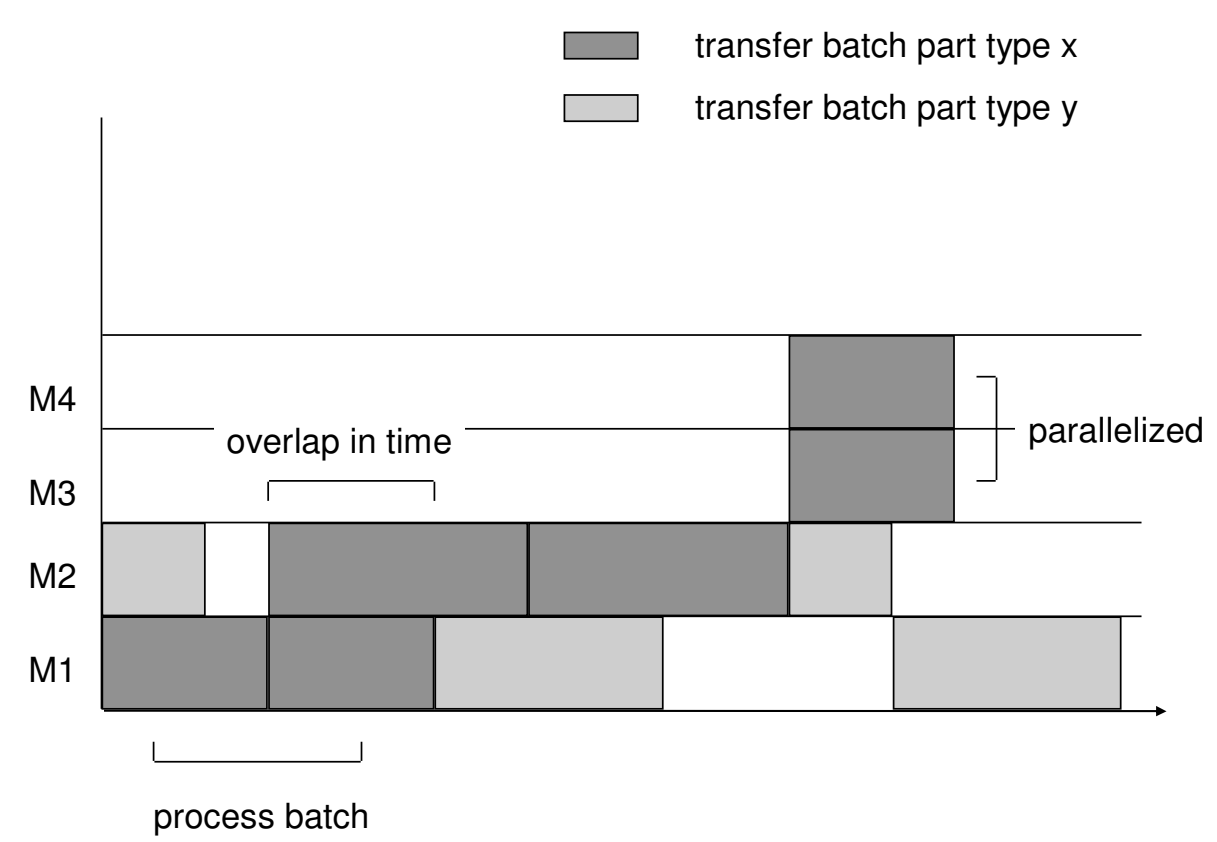

Fig. 1 Scheduling transfer batches in a modern job shop

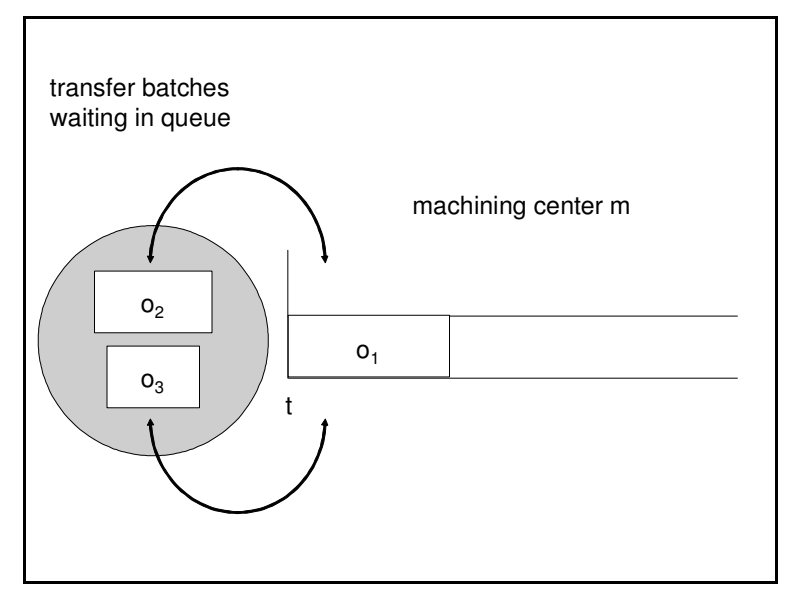

Fig. 2(a) Transition mechanism 1

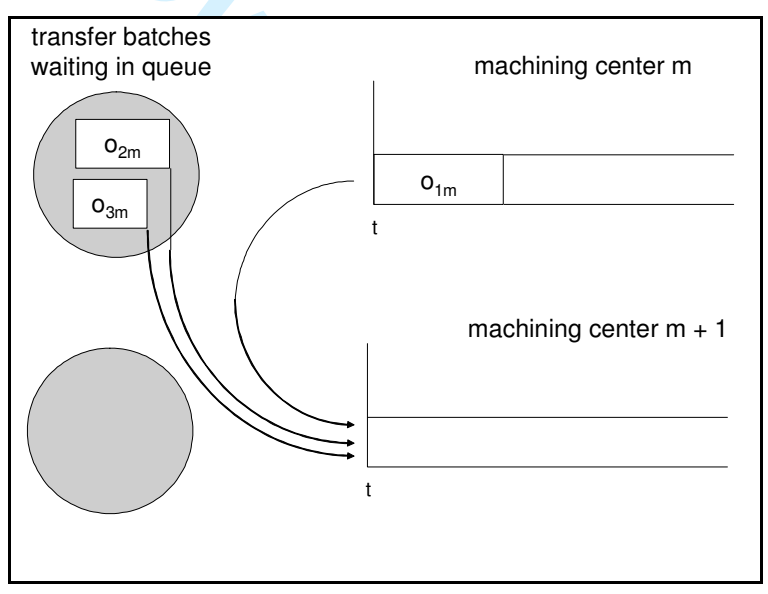

Fig. 2(b) Transition mechanism 2 
part type order:

14 housings ( part type 7107)

operation 1,2

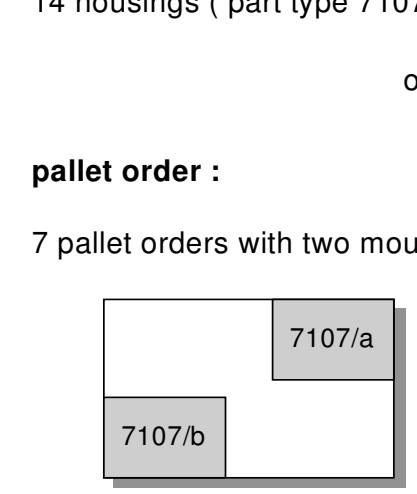

1. mount

First operations 1,2 are performed on 7107/a and $71107 / \mathrm{b}$; afterwards the pallet ist automatically turned by $180^{\circ}$ on the local input/output buffer in order to perform operation 4 on both parts.

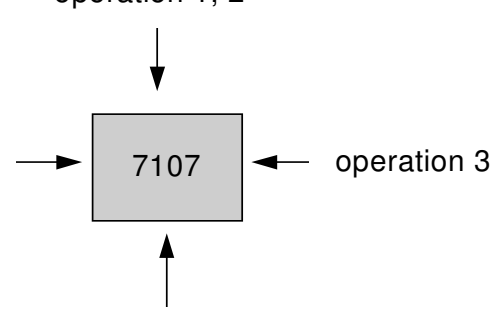

operation 4

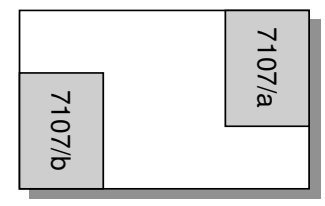

2. mount

The procedure is repeated on the secound mount in order to perform operations 5,6 and 3 on both parts.

\section{Fig. $3 \quad$ FMC pallet orders}

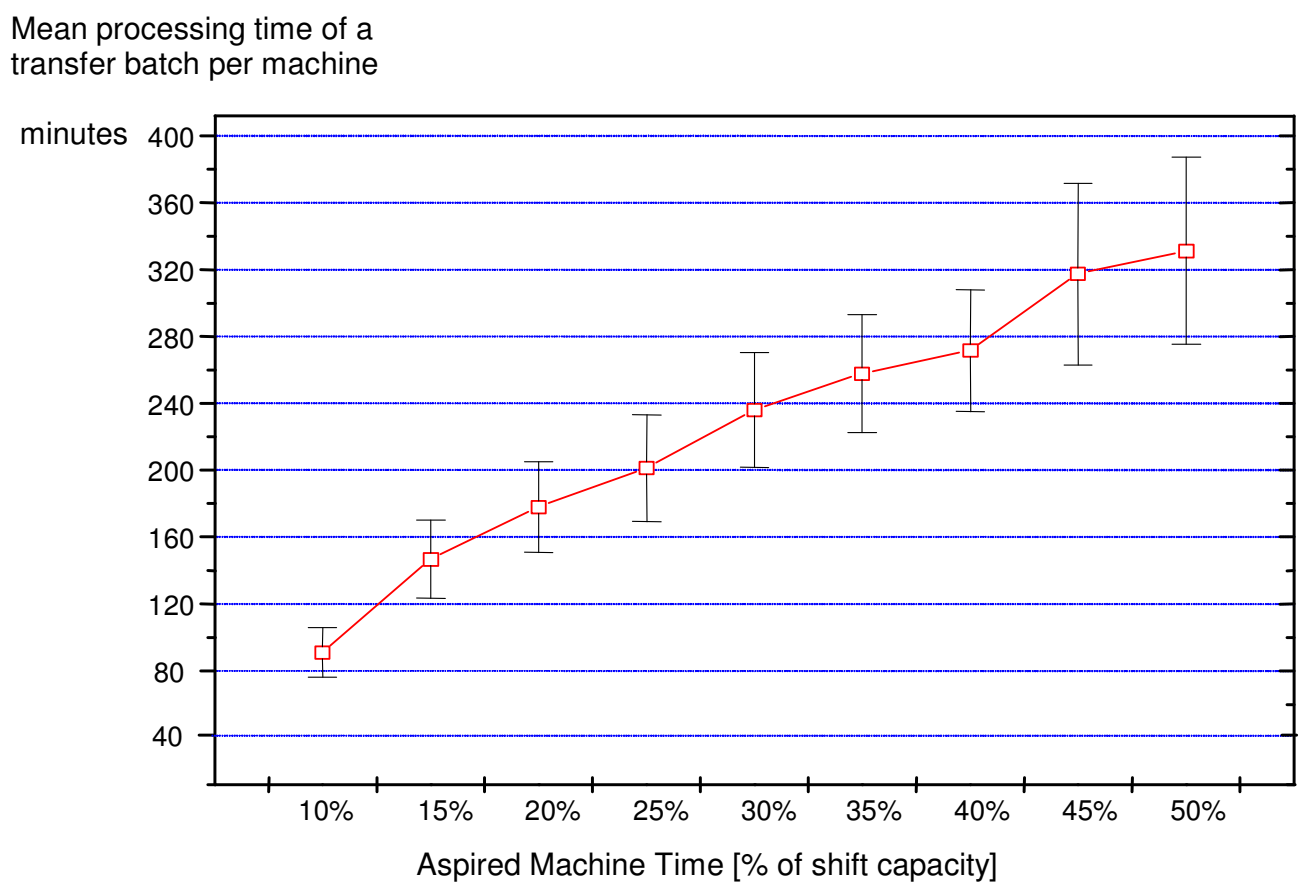

Fig. 4 Mean processing time of the transfer batches 


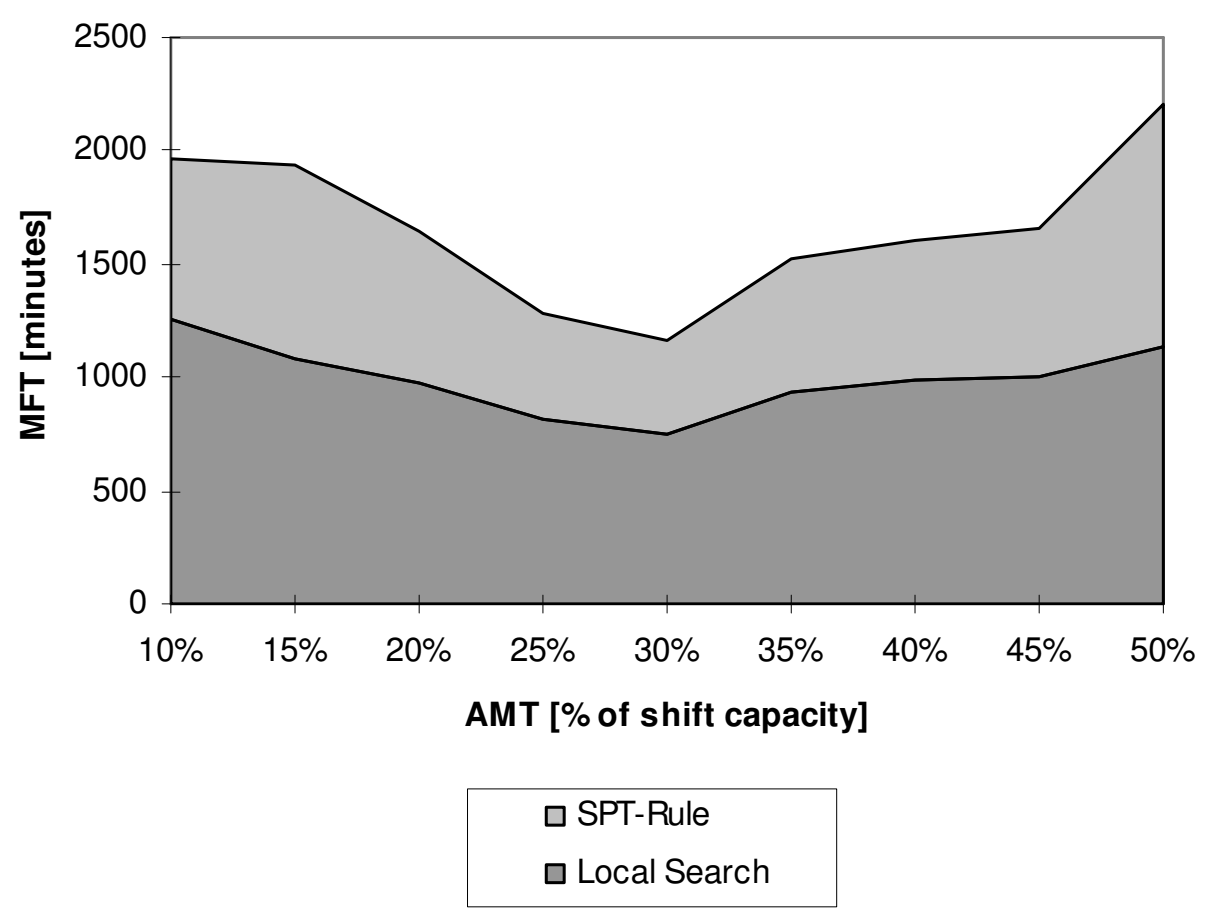

Figure 5 Performance of local search depending on AMT 